\title{
A Pilot Study of the Effect of Green Kiwifruit on Human Intestinal Fermentation Measured by Hydrogen and Methane Breath Testing
}

\author{
Amanda G.Y. Chen, ${ }^{1, *}$ Marleen S.L. Offereins, ${ }^{1,2, *}$ Christopher J. Mulder, \\ Christopher M. Frampton, and Richard B. Gearry ${ }^{1}$ \\ ${ }^{1}$ Department of Gastroenterology and Medicine, Christchurch Hospital, University of Otago, Christchurch, \\ Christchurch, New Zealand. \\ ${ }^{2}$ Department of Medicine, VU Medical Centre, Amsterdam, The Netherlands.
}

\begin{abstract}
We investigated the impact of the ingestion of two green kiwifruit (Actinidia deliciosa var. Hayward) and one Royal Gala apple on breath hydrogen and methane production in humans. Consumption of two green kiwifruit led to no evidence of carbohydrate malabsorption (0/20), whereas consumption of one apple was associated with carbohydrate malabsorption in $6 / 20$ participants $(P=.008)$. There were no significant differences in the area under the curve for hydrogen or methane breath concentrations after consumption of the two fruits. Rates of lactose and fructose breath tests in this cohort were within expected parameters. Green kiwifruit are not associated with clinically significant carbohydrate malabsorption compared with apples in this pilot study.
\end{abstract}

\section{KEYWORDS: • breath testing • FODMAP • intestinal fermentation $\bullet$ irritable bowel syndrome $\bullet$ kiwifruit}

$\mathbf{F}$ UNCTIONAL GASTROINTESTINAL DISORDERS (FGDs), including irritable bowel syndrome (IBS), affect over $20 \%$ of the population, leading to significant morbidity and healthcare expenditure. ${ }^{1,2}$ The etiology of FGDs is poorly understood, but may include disorders of the brain-gut axis, visceral afferent hypersensitivity, and gastrointestinal dysbiosis. ${ }^{3}$ Different foods may trigger gastrointestinal symptoms such as diarrhea, abdominal bloating, wind, and pain, and most patients identify dietary change as an effective means of controlling symptoms. ${ }^{4}$ For some foods, there is a clear mechanism for the pathogenesis of gastrointestinal symptoms, while the mechanisms of symptom generation are less well understood for other foods. In recent years, FODMAPs (fermentable oligo-, mono-, and disaccharides and polyols), a group of nonabsorbed rapidly fermented carbohydrates, have been described as potent triggers of gastrointestinal symptoms in people with IBS., ${ }^{5,6}$ Low FODMAP diet and the exclusion of other food groups have been subjects of increasing research. ${ }^{7}$ However, there have

\footnotetext{
*Joint first authors.
}

Manuscript received 11 January 2018. Revision accepted 28 March 2018.

Address correspondence to: Richard B. Gearry, $M B C h B, P h D$, Department of Gastroenterology and Medicine, Christchurch Hospital, University of Otago, Christchurch, PO Box 4345, Christchurch 8011, New Zealand, E-mail: richard.gearry@cdhb.govt.nz

(C) Amanda G.Y. Chen et al., 2018; Published by Mary Ann Liebert, Inc. This openaccess article is distributed under the terms of the Creative Commons License (http:// creativecommons.org/licenses/by/4.0), which permits unrestricted use, distribution, and reproduction in any medium, provided the original work is properly cited. been few human studies describing whole food digestion, which may exacerbate gut symptoms.

The ingestion of two green kiwifruit (Actinidia deliciosa var. Hayward) daily has been shown to improve abdominal symptoms in those with constipation, ${ }^{8,9}$ although the mechanism is poorly understood. ${ }^{10}$ While there has been no signal of increased abdominal bloating or diarrhea in individuals consuming kiwifruit in these clinical studies, other treatments for constipation and gastrointestinal discomfort are associated with such adverse effects. ${ }^{11}$ Hydrogen and methane breath testing has been used in humans routinely to demonstrate excessive intestinal fermentation, which may be associated with gastrointestinal symptoms such as diarrhea and abdominal pain and bloating. ${ }^{12} \mathrm{We}$ aimed to compare gastrointestinal fermentation patterns following the ingestion of lactulose, fructose, and lactose (standard test substrates) and the whole foods of two green kiwifruit and one apple (both standard serving sizes) in people with IBS and healthy controls.

Twenty participants (10 IBS and 10 controls) took part in this prospective, nonrandomized, nonblinded, clinical pilot study. This number of participants was discussed with a biostatistician and identified as being appropriate for a pilot study of this type. Cases were identified from outpatient clinics referred by gastroenterologists for diagnostic breath testing and dietary manipulation for the management of IBS. Ten healthy controls were recruited from the community. Inclusion criteria included participant age between 18 and 65 years with a body-mass index of between 18 and $35 \mathrm{~kg} / \mathrm{m}^{2}$. Those with IBS needed to fulfill the Rome III diagnostic 
Table 1. Characteristics of the Study Groups

\begin{tabular}{lccc}
\hline Patient variable & $\begin{array}{c}\text { Healthy } \\
\text { participants }\end{array}$ & $\begin{array}{c}\text { IBS } \\
\text { patients }\end{array}$ & Total \\
\hline $\begin{array}{l}\text { Sex, male/female } \\
\text { Age, median (range), } \\
\quad \text { years }\end{array}$ & $0 / 10$ & $0 / 10$ & $0 / 20$ \\
$\begin{array}{l}\text { BMI, median (range), } \\
\text { kg/m }\end{array}$ & $25.2(19-31)$ & $36(18-54)$ & $40.5(18-62)$ \\
$\begin{array}{l}\text { Smoking, } n(\%) \\
\begin{array}{l}\text { Alcohol, median, } \\
\text { units/week }\end{array}\end{array}$ & $1(10)$ & 0 & $1(5)$ \\
\hline
\end{tabular}

BMI, body-mass index; IBS, irritable bowel syndrome.

criteria. ${ }^{13}$ Those with other gastrointestinal disorders such as inflammatory bowel disease, diverticulosis, colorectal cancer or polyposis, or bowel resection; other significant health conditions (e.g., diabetes, cardiovascular, or neurological disease); were pregnant or breastfeeding; or had allergies to a test substrate were excluded.

All participants underwent five breath tests over five nonconsecutive days using established and validated methodology. ${ }^{14,15}$ Participants followed a low fermentable diet for 24 hours before each test and were nil by mouth for 10 hours before testing. Breath samples were tested at baseline for $\mathrm{H}_{2}$ and $\mathrm{CH}_{4}$ concentrations and then every 15 minutes for at least 3 hours after ingestion of each substrate (lactulose $15 \mathrm{~g}$, fructose $35 \mathrm{~g}$, lactose $50 \mathrm{~g}$, one Royal Gala apple [125g], and two Zespri ${ }^{\mathrm{TM}}$ green kiwifruit [190 g]) using a Quitron Microlyser (Quintron Instrument Co., Milwaukee, WI, USA). The primary outcome for the study was the proportion of participants with positive breath hydrogen (rise $>10 \mathrm{ppm}$ for greater than two consecutive recordings) or breath methane (rise $>20 \mathrm{ppm}$ for greater than two con- secutive recordings) tests following the ingestion of each substrate as a measure of clinically significant intestinal fermentation. Secondary outcomes included the area under the curve (AUC) for both $\mathrm{H}_{2}$ and $\mathrm{CH}_{4}$ production. Ethical approval was given by the University of Otago Human Ethics Committee (H16/008). Written informed consent was obtained from all participants.

Chi-square tests were used to compare the number of positive tests between each group. Friedman's test was used to compare the AUC values from the breath tests. Pairwise comparisons were undertaken using the Wilcoxon signedrank test when significant differences among the substrates were found (IBM SPSS Statistics, version 23). A value of $P<.05$ was considered statistically significant.

All participants performed the five breath tests except for one participant who did not return for the fructose breath test and was lost to follow-up. There were no significant demographic baseline differences between cases and controls ( $\mathrm{Ta}-$ ble 1). Regarding the primary outcome of the study, there were significantly fewer positive breath tests following the ingestion of two green kiwifruit $(0 / 20)$ compared with the positive control lactulose $(14 / 20, P<.001)$, fructose $(4 / 20, P=.04)$, lactose $(4 / 20, P=.04)$, and apple $(6 / 20, P=.008)$ (Table 2$)$.

The mean AUC for $\mathrm{CH}_{4}(32$ vs. $171 \mathrm{ppm}, P=.041)$ and $\mathrm{H}_{2}$ (14 vs. $1569 \mathrm{ppm}, P=.01$ ) production was significantly lower for green kiwifruit than the positive control lactulose. The $\mathrm{CH}_{4}$ and $\mathrm{H}_{2}$ AUCs for kiwifruit were nonsignificantly lower than for fructose, lactose, and apple. Rates of fructose and lactose-positive breath tests were consistent with population rates. There were no differences in the AUCs between the control and IBS groups $(P>.05)$.

This pilot study has demonstrated no evidence of clinically significant carbohydrate malabsorption following the ingestion of two green kiwifruit in a cohort of healthy controls and adults with IBS. Rates of breath test positivity

Table 2. Breath Test Results of Study Participants

\begin{tabular}{|c|c|c|c|}
\hline Patient variable & Healthy participants & IBS patients & Total \\
\hline Positive BT after lactulose & $7(70 \%)$ & $7(70 \%)$ & $14(70 \%)^{\mathrm{a}}$ \\
\hline Positive BT after fructose & $2(22 \%)$ & $2(20 \%)$ & $4(21 \%)^{\mathrm{a}}$ \\
\hline Positive BT after lactose & $2(20 \%)$ & $2(20 \%)$ & $4(20 \%)^{\mathrm{a}}$ \\
\hline Positive BT after 2 green kiwifruit & 0 & 0 & 0 \\
\hline Positive BT after one apple & $3(30 \%)$ & $3(30 \%)$ & $6(30 \%)^{\mathrm{a}}$ \\
\hline Kiwifruit BT $\left(\mathrm{H}_{2}\right.$ AUC), mean $(\mathrm{SD})^{\mathrm{b}}$ & $71(294)$ & $3(487)$ & $14(400)^{\mathrm{c}}$ \\
\hline Kiwifruit BT $\left(\mathrm{CH}_{4}\right.$ AUC), mean (SD) ${ }^{\mathrm{b}}$ & $70(233)$ & $0(261)$ & $32(244)$ \\
\hline Lactulose BT $\left(\mathrm{H}_{2}\right.$ AUC), mean (SD) ${ }^{\mathrm{b}}$ & $1056(1226)$ & $2082(3716)$ & $1569(2744)^{\mathrm{c}}$ \\
\hline Lactulose BT $\left(\mathrm{CH}_{4}\right.$ AUC), mean (SD) ${ }^{\mathrm{b}}$ & $98(511)$ & $245(765)$ & $171(638)$ \\
\hline Fructose BT $\left(\mathrm{H}_{2}\right.$ AUC), mean $(\mathrm{SD})^{\mathrm{b}}$ & $597(1687)$ & $1163(2930)$ & $895(2376)$ \\
\hline Fructose $\mathrm{BT}\left(\mathrm{CH}_{4} \mathrm{AUC}\right)$, mean $(\mathrm{SD})^{\mathrm{b}}$ & $73(132)$ & $314(734)$ & $200(541)$ \\
\hline Lactose BT $\left(\mathrm{H}_{2}\right.$ AUC), mean $(\mathrm{SD})^{\mathrm{b}}$ & $1109(4635)$ & $341(526)$ & $725(3235)$ \\
\hline Lactose BT $\left(\mathrm{CH}_{4}\right.$ AUC), mean (SD) ${ }^{\mathrm{b}}$ & $13(108)$ & $154(340)$ & $60(264)$ \\
\hline Apple BT $\left(\mathrm{H}_{2}\right.$ AUC $)$, mean $(\mathrm{SD})^{\mathrm{b}}$ & $86(355)$ & $0(784)$ & $68(593)$ \\
\hline Apple BT $\left(\mathrm{CH}_{4}\right.$ AUC), mean (SD) ${ }^{\mathrm{b}}$ & $167(384)$ & $138(267)$ & $152(308)$ \\
\hline
\end{tabular}

${ }^{b}$ Measurements in parts per million $\mathrm{H}_{2}$ or $\mathrm{CH}_{4}$.

${ }^{a}$ Significant difference between rates of positive breath tests after substrate compared with kiwifruit $(P<.05)$.

${ }^{c} P<.05$ using both Freidman's and Wilcoxon signed-rank tests.

AUC, area under the curve; BT, breath test. 
for fructose, lactose, and the positive control lactulose in this mixed cohort were within expected population ranges. ${ }^{16} \mathrm{H}_{2}$ and $\mathrm{CH}_{4}$ breath testing is used to diagnose individuals with carbohydrate malabsorption that may trigger gut symptoms. ${ }^{15,17}$ Consumption of two green kiwifruit daily has been shown in clinical trials to reduce constipation and to improve abdominal discomfort ${ }^{8,9}$ and, in the present study, this has not been associated with clinically significant carbohydrate malabsorption. This suggests that kiwifruit may be less likely to induce luminal distension and abnormal gas handling in the colon, both of which may lead to abdominal bloating, flatus, and discomfort. ${ }^{18}$

Green kiwifruit are low in free fructose, which may be poorly absorbed and rapidly fermented in some individuals. ${ }^{19}$ There are similar amounts of fructose and glucose ( 4.68 and $4.13 \mathrm{~g} / 100 \mathrm{~g}$ of edible flesh, respectively) in green kiwifruit, facilitating cotransport across the apical membrane into the enterocyte. ${ }^{20,21}$ Additionally, there are negligible amounts of other nonabsorbed carbohydrates that could act as substrates for colonic fermentation. ${ }^{22}$

This pilot study, surprisingly, demonstrated clinically significant increases in breath $\mathrm{H}_{2}$ or $\mathrm{CH}_{4}$ (consistent with malabsorption of the substrate using accepted criteria) in $30 \%$ of participants following the ingestion of one apple. Apples contain $5.9 \mathrm{~g}$ of fructose and $2.4 \mathrm{~g}$ of glucose. While this amount of free fructose would seem unlikely to lead to clinically significant malabsorption, free fructose, in addition to sorbitol, may make apples more likely to trigger gut symptoms in some people with IBS. Other potential explanations for the findings relate to differences in the fruit matrix and digestion in the small intestine. Fiber content is unlikely to lead to significant differences in colonic fermentation given that the fiber content for two green kiwifruit and one Royal Gala apple is 5.8 and $2.6 \mathrm{~g}$, respectively. ${ }^{19}$

This pilot study is not without limitations. First, the number of participants is small, all female, and the findings need to be replicated in a larger group of participants. Furthermore, while there were trends, no significant differences were seen between the kiwifruit and other substrate AUCs (with the exception of the positive control lactulose), which may have supported these findings. The duration of breath testing following the ingestion of substrates may not have been long enough to capture significant colonic fermentation that could have occurred after the 3-hour window. However, the final breath test recordings at 3 hours were approaching baseline in all individuals and it is likely that such delays will have affected breath test recordings for both fruits equally. It is also possible that malabsorption of other components of the kiwifruit could have led to symptoms. Other measures of colonic fermentation such as measurement of short-chain fatty acids in the fecal stream were not performed in this pilot study and may lead to a deeper understanding of the fate of kiwifruit digesta in the colon in humans. ${ }^{23}$ In conclusion, the consumption of two green kiwifruit was not associated with evidence of clinically significant colonic fermentation in the 3 hours after consumption in a mixed population of IBS and healthy participants.

\section{ACKNOWLEDGMENT}

This work was funded by Zespri International Limited.

\section{ETHICAL APPROVAL}

All procedures performed in studies involving human participants were in accordance with the ethical standards of the institutional and/or national research committee and with the 1964 Helsinki Declaration and its later amendments or comparable ethical standards.

\section{AUTHOR DISCLOSURE STATEMENT}

Dr. Richard B. Gearry has received funding from Zespri International Limited for this and related research, travel assistance, and expenses toward attending scientific conferences. For all other authors, no competing financial interests exist.

\section{REFERENCES}

1. Canavan C, West J, Card T: The epidemiology of irritable bowel syndrome. Clin Epidemiol 2014;6:71-80.

2. Canavan C, West J, Card T: Review article: The economic impact of the irritable bowel syndrome. Aliment Pharmacol Ther 2014;40:1023-1034.

3. Enck P, Aziz Q, Barbara G, et al.: Irritable bowel syndrome. Nat Rev Dis Primers 2016;2:16014.

4. Quigley EM, Abdel-Hamid H, Barbara G, et al.: A global perspective on irritable bowel syndrome: A consensus statement of the World Gastroenterology Organisation Summit Task Force on irritable bowel syndrome. J Clin Gastroenterol 2012;46:356-366.

5. Kortlever T, Hebblethwaite C, Leeper J, O'Brien L, Mulder C, Gearry RB: Low FODMAP diet efficacy in IBS patients-what is the evidence and what else do we need to know? N Z Med J 2016; 129:75-83.

6. Nanayakkara WS, Skidmore PM, O’Brien L, Wilkinson TJ, Gearry RB: Efficacy of the low FODMAP diet for treating irritable bowel syndrome: The evidence to date. Clin Exp Gastroenterol 2016;9:131-142.

7. Staudacher HM, Irving PM, Lomer MC, Whelan K: Mechanisms and efficacy of dietary FODMAP restriction in IBS. Nat Rev Gastroenterol Hepatol 2014;11:256-266.

8. Chan AO, Leung G, Tong T, Wong NY: Increasing dietary fiber intake in terms of kiwifruit improves constipation in Chinese patients. World J Gastroenterol 2007;13:4771-4775.

9. Chang CC, Lin YT, Lu YT, Liu YS, Liu JF: Kiwifruit improves bowel function in patients with irritable bowel syndrome with constipation. Asia Pac J Clin Nutr 2010;19:451-457.

10. Bayer SB, Gearry RB, Drummond LN: Putative mechanisms of kiwifruit on maintenance of normal gastrointestinal function. Crit Rev Food Sci Nutr 2017:0.

11. Trinkley KE, Nahata MC: Medication management of irritable bowel syndrome. Digestion 2014;89:253-267.

12. Rezaie A, Buresi M, Lembo A, et al.: Hydrogen and methanebased breath testing in gastrointestinal disorders: The North American Consensus. Am J Gastroenterol 2017;112:775-784.

13. Longstreth GF, Thompson WG, Chey WD, Houghton LA, Mearin F, Spiller RC: Functional bowel disorders. Gastroenterology 2006;130:1480-1491. 
14. Barrett JS, Canale KE, Gearry RB, Irving PM, Gibson PR: Probiotic effects on intestinal fermentation patterns in patients with irritable bowel syndrome. World J Gastroenterol 2008;14:5020-5024.

15. Eisenmann A, Amann A, Said M, Datta B, Ledochowski M: Implementation and interpretation of hydrogen breath tests. $J$ Breath Res 2008;2:046002.

16. Barrett JS, Irving PM, Shepherd SJ, Muir JG, Gibson PR: Comparison of the prevalence of fructose and lactose malabsorption across chronic intestinal disorders. Aliment Pharmacol Ther 2009;30:165-174.

17. Rumessen JJ, Gudmand-Hoyer E: Functional bowel disease: Malabsorption and abdominal distress after ingestion of fructose, sorbitol, and fructose-sorbitol mixtures. Gastroenterology 1988; 95:694-700.

18. Ong DK, Mitchell SB, Barrett JS, et al.: Manipulation of dietary short chain carbohydrates alters the pattern of gas production and genesis of symptoms in irritable bowel syndrome. $J$ Gastroenterol Hepatol 2010;25:1366-1373.
19. Sivakumaran S, Huffman L: The Concise New Zealand Food Composition Tables. (Sivakumaran S, ed.) The New Zealand Institute for Plant and Food Research Limited and Ministry of Health, Palmerston North, New Zealand, 2017.

20. Truswell AS, Seach JM, Thorburn AW: Incomplete absorption of pure fructose in healthy subjects and the facilitating effect of glucose. Am J Clin Nutr 1988;48:1424-1430.

21. Helliwell PA, Richardson M, Affleck J, Kellett GL: Stimulation of fructose transport across the intestinal brush-border membrane by PMA is mediated by GLUT2 and dynamically regulated by protein kinase C. Biochem J 2000;350 Pt 1:149-154.

22. Drummond L: The composition and nutritional value of kiwifruit. Adv Food Nutr Res 2013;68:33-57.

23. Parkar SG, Rosendale D, Paturi G, et al: In vitro utilization of gold and green kiwifruit oligosaccharides by human gut microbial populations. Plant Foods Hum Nutr 2012;67:200207. 